\title{
An Analysis on the Relationships of Tax Official's Adversity Quotient Factor with Their Resilience and Job Performance
}

\author{
Soon-Bok Hong \\ Department of Business Administration Tong-Myung University, Busan, South Korea \\ hong6601@hanmail.net
}

\begin{abstract}
According as the scope of tax administration service has widened to comprise the complex functions of welfare tax administration, beyond the simple taxation of the past, in response to the needs of the times, the workload of front-line tax officials who meet taxpayers face-to-face is rapidly increasing. This study, we propose that the relationship between adversity quotient factors and job performance will be different in their adaptive flexibility by using adaptive flexibility as a moderating variable. In addition, this study empirically analyzes the relationship between adversity quotient factors and job performance based on resilience by breaking away from fragmentary causal relationship. This study aims to investigate the impacts of revenue officers ' adversity quotient factors (control, ownership, reach, endurance) on job performance and empirically analyze the context of their relationships, using the moderator variable of resilience concerning whether there are differences in adversity quotient factors affecting job performance according to resilience. As a result of an empirical analysis, adversity quotient factors had significant positive impacts on job performance, and as a result of an analysis of the interaction terms of regulation effect analysis, of the adversity quotient factors, except for control and continuity, ownership (ownership $x$ resilience) and reach (reach $x$ resilience) had statistically significant positive impacts on job performance.
\end{abstract}

Keywords: Adversity, Adversity quotient factors, Resilience, Job performance, Tax officer

\section{Introduction}

Tax administration service is an agency levying tax that provides not only the work as a simple tax institution but also the complex function like welfare cleaning work. In accordance to various needs of the times, the workload of the tax officials who face the taxpayers directly is increasing rapidly. The officials need to be equipped with technical expertise related to taxation and are required for heavy workload, responsibility, and work performance due to various needs of taxpayers. In addition, they are facing various and complicated adversities in the customer service such as technical limitations, and friction with colleagues, bosses, and taxpayers in their job performance.

For these above reasons, in order to overcome such adversities in their acts of tax administration, today's tax officials are required to be equipped with cognitive and behavioral capacity to treat problems. Accordingly, this study examine the moderating effect of resilience in the relationship between adversity quotient factors and job performance. Important personal competence and competence factors related to job performance for the tax official are adversity

Article history:

Received (February 8, 2020), Review Result (March 11, 2020), Accepted (April 20, 2020) 
and resilience because they have physical responsibility for securing tax revenue. As a representative indicator of the effectiveness of organizational management, job performance is very important for active organization as it becomes a very important standard to achieve the goal of individual work. [1] Job performance is a degree of improvement of given work performance and successfully performed work [2], and provides not only managerial decisions such as training and compensation but also information on improvement or termination of performance [3].

\section{Theoretical background}

The adversity quotient was made to evaluate the ability to achieve goals by challenging without succumbing to many adversities, and this can be seen as a capacity, productivity, and innovation within an organization [4]. Adversity means personal and environmental characteristics related to negative development. [5] Adversity quotient factors are concepts understood in a broad sense, which include emotional intelligence, self-efficacy, and selfcontrol that are closely related to job satisfaction and adaptation to organization in individual aspects.

Control means personal control in crisis, and ownership is personal initiative to overcome crisis. Reach means the influence on other parts of individuals' lives in the event of a crisis. Endurance means how long they perceive the situation of crisis lasts. Adversity quotient factors, which are variables that can explain the organizational adaptation of workers, are closely related to resilience and emotional intelligence. Especially, it is an important competency factor highly related to job performance. In a rapidly changing and diverse competitive society, we cannot help but face many adversities. Among them, the more cases of overcoming and succeeding in inevitable and difficult adversity, the more adversity quotient is noteworthy as a capability indicator. The adversity quotient factor is the internal factor for the organizational adjustment of tax officials because the utilization value for practical application is high. There are no publications and theses studying the quotient. In addition, there are few studies on adversity quotient factors, which can be a plan to increase organizational adaptation that actually affects job performance.

Resilience [6] is defined as a process of dynamic change through interaction with the environment by understanding qualitatively positive adaptation to various adversities. Resilience, given the assumption that one shall be exposed to severe risks and serious misfortunes, is the concept emphasizing that even if the work process faces a great threat, it should acquire positive adaptations that meet the developmental tasks and social expectations required in the social context.[7][8]

Job performance, which refers to organizational members' successful achievement on the job, can be analyzed based on the quantitative and qualitative performance and the propulsion of work [9]. The evaluation was based on the reduction of trial and error, the degree of utilization on the task, and the improvement of the job performance [10].

\section{Research design}

\subsection{Research model and hypothesis setting}

This study aims to approach the effect of adversity quotient factors on job performance from a comprehensive perspective by using a moderating variable of adversity quotient factors that an independent variable of adversity quotient factors will be different in accordance to adversity flexibility. This study is expected to be provided as basic data for job establishment and 
performance management for tax officials so that they can perform their job efficiently. So, a study model in [Figure 1] is proposed based on theoretical backgrounds and existing precedents. This study bases the degree of quality and quantity achieved by tax officials and that of execution successfully made on job performance.

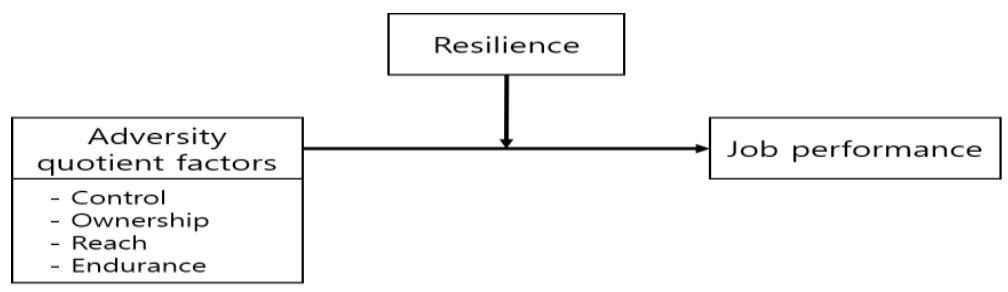

Figure 1. Research model

This study is about the moderating role of resilience in the relationship between adversity quotient factors and job performance. Through the perception of adversity quotient factors, organizational members exert flexibility in thinking in the job performance process, which has a positive effect on job performance. Therefore, in order to achieve the successful job performance of tax officials, it is important to identify the causal relationship between the adversity quotient factors, resilience and job performance in the process of performing the work.

Based on the above theoretical bases and precedents, this study sets up hypothesis 1 , and it does so on hypothesis 2 in that, though adversity quotient factors have a relevant effect on job performance, resilience has a moderating effect in relation to adversity quotient and job performance.

H1: Adversity quotient factors will affect job performance.

1-1: Control will have a positive (+) effect.

1-2: Ownership will have a positive (+) effect on job performance

1-3: Scope will have a positive $(+)$ effect on job performance.

1-4: Consistency will have a positive (+) effect on job performance.

$\mathrm{H} 2$ : Resilience will moderate the relationship between adversity quotient factors and job performance.

2-1: Resilience will moderate the relationship between control and job performance.

2-2: Resilience will moderate the relationship between ownership and job performance.

2-3: Resilience will moderate the relationship between scope and job performance.

2-4: Resilience will moderate the relationship between consistency and job performance.

\subsection{Research subject and operational definition}

The sample of this study was collected from tax officials working at tax offices in Busan and Gyeong-nam in June 2019. A total of 267 subjects were selected and 255 questionnaires were finally used for this study, excluding 12 unrecovered questionnaires and 12 unfaithful questionnaires. The survey period was from June 9 to July 10, 2019, for a total of 31 days.

To develop the questionnaires to verify the research hypothesis, the operational definition of the variables was set as follows. The adversity quotient is a measure of human ability to overcome adversity and how humans overcome adversity. It is composed of a measure of 
control, ownership, reach, and endurance developed as a measure of who is the person that can overcome the crisis when an individual faces a crisis.

Resilience refers to the ability to adaptively transform cognitive frameworks in accordance with the stimulus of changing environment. This study modified and used the scales which had been developed by Dennis \& Vander Wal(2010).

Organizational performance is an indicator of the effectiveness of organizational management as the achieved degree of the work of the organization members, which is also an important standard to measure the achievement of individual work goals.

\section{Empirical analysis}

\subsection{Validity and reliability of variables}

The factor analysis shows that all the scales used to measure the variables in [Table 1] have appropriate convergence and discriminant validity. Also, the level of reliability level for each variable was mostly high, which turns out to be appropriate for analysis in this study.

Table 1 The result of factor analysis on research variables

\begin{tabular}{|c|c|c|c|c|c|c|}
\hline \multicolumn{2}{|c|}{ Variables } & Items measured & $\begin{array}{c}\text { Factor loading } \\
\text { value }\end{array}$ & Eigenvalue & $\begin{array}{c}\text { cumulative description } \\
\text { dispersion }(\%)\end{array}$ & $\operatorname{Reliability}(\alpha)$ \\
\hline \multirow{4}{*}{$\begin{array}{c}\text { Adversity } \\
\text { quotient } \\
\text { factor }\end{array}$} & Control & $\begin{array}{l}\text { control } 1 \\
\text { control } 2 \\
\text { control } 3\end{array}$ & $\begin{array}{l}.748 \\
.678 \\
.647\end{array}$ & 1.814 & 61.151 & .689 \\
\hline & Ownership & $\begin{array}{l}\text { ownership } 1 \\
\text { ownership } 2 \\
\text { ownership } 3 \\
\text { ownership } 4 \\
\text { ownership } 5\end{array}$ & $\begin{array}{l}.722 \\
.712 \\
.704 \\
.697 \\
.617\end{array}$ & 3.013 & 24.535 & .795 \\
\hline & Reach & $\begin{array}{l}\text { reach } 1 \\
\text { reach } 2 \\
\text { reach } 3 \\
\text { reach } 4 \\
\end{array}$ & $\begin{array}{l}.749 \\
.689 \\
.638 \\
.632 \\
\end{array}$ & 2.277 & 54.445 & .756 \\
\hline & Endurance & $\begin{array}{l}\text { endurance } 1 \\
\text { endurance } 2 \\
\text { endurance } 3 \\
\text { endurance } 4 \\
\text { endurance } 5\end{array}$ & $\begin{array}{l}.767 \\
.723 \\
.660 \\
.648 \\
.628 \\
\end{array}$ & 2.940 & 35.425 & .808 \\
\hline \multicolumn{2}{|c|}{ Resilience } & $\begin{array}{l}\text { resilience } 1 \\
\text { resilience } 2 \\
\text { resilience } 3 \\
\text { resilience } 4 \\
\text { resilience } 5\end{array}$ & $\begin{array}{l}.795 \\
.759 \\
.749 \\
.634 \\
.627\end{array}$ & 2.859 & 46.013 & .804 \\
\hline \multicolumn{2}{|c|}{ Job performance } & $\begin{array}{l}\text { job performance } 1 \\
\text { job performance } 2 \\
\text { job performance } 3 \\
\text { job performance } 4 \\
\text { job performance } 5\end{array}$ & $\begin{array}{l}.847 \\
.821 \\
.758 \\
.745 \\
.740\end{array}$ & 3.611 & 13.374 & .880 \\
\hline
\end{tabular}

\subsection{Hypothesis test}

The results of moderated multiple regression were presented in [Table 2] to test the hypothesis that resilience would have a moderating effect on the relationship between the adversity quotient factors on the part of tax officials and their job performance. 
Table 2. The result of moderating regression analysis on job performance

\begin{tabular}{|c|c|c|c|c|c|c|c|c|c|}
\hline & \multicolumn{3}{|c|}{$[$ model 1] } & \multicolumn{3}{|c|}{ [model 2] } & \multicolumn{3}{|c|}{ [model 3] } \\
\hline & $\mathrm{B}$ & B & p-Value & B & B & p-Value & $\mathrm{B}$ & B & p-Value \\
\hline (constant) & 2.082 & & & 1.585 & & & 1.091 & & \\
\hline control & .111 & .118 & $.044 * *$ & .084 & .089 & .124 & .072 & .076 & .858 \\
\hline ownership & .243 & .248 & $.019 * *$ & .178 & .182 & $.002 * * *$ & .137 & .163 & $.044 * *$ \\
\hline reach & .122 & .147 & $.000 * * *$ & .116 & .140 & $.022 * *$ & .136 & .175 & $.031 * *$ \\
\hline endurance & .095 & .133 & $.038 * *$ & .067 & .095 & .134 & .347 & .488 & .241 \\
\hline resilience & & & & .253 & .232 & $.000 * * *$ & .366 & .336 & $.048 * *$ \\
\hline control x resilience & & & & & & & -.005 & .028 & .964 \\
\hline ownership x resilience & & & & & & & .219 & .172 & $.008 * * *$ \\
\hline reach $\mathrm{x}$ resilience & & & & & & & .149 & .238 & $.013 * *$ \\
\hline endurance $\mathrm{x}$ resilience & & & & & & & -.075 & -.516 & .339 \\
\hline revised R2 & \multicolumn{3}{|c|}{.214} & \multicolumn{3}{|c|}{.253} & \multicolumn{3}{|c|}{.251} \\
\hline R2's amount of change & \multicolumn{3}{|c|}{.225} & \multicolumn{3}{|c|}{.266} & \multicolumn{3}{|c|}{.273} \\
\hline F's amount of increase & \multicolumn{3}{|c|}{21.495} & \multicolumn{3}{|c|}{21.304} & \multicolumn{3}{|c|}{12.112} \\
\hline significant proabability & \multicolumn{3}{|c|}{$.000 * * *$} & \multicolumn{3}{|c|}{$.000 * * *$} & \multicolumn{3}{|c|}{$.000 * * *$} \\
\hline \multicolumn{10}{|c|}{ 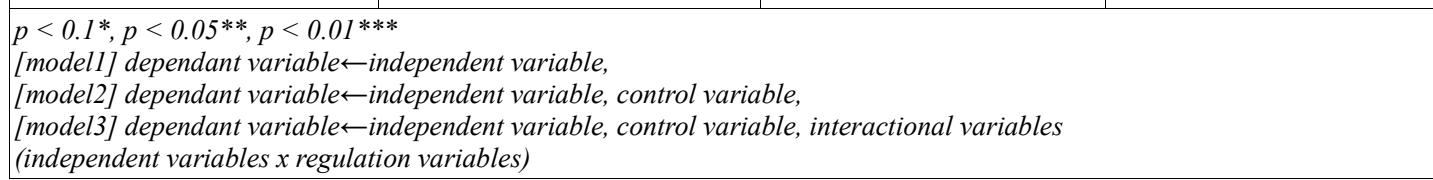 } \\
\hline
\end{tabular}

As a result of the analysis, the total explanatory power of the regression model set with control, ownership, reach, and endurance as independent variables was $21 \%(\mathrm{R} 2=.214)$ and $\mathrm{F}=21.495$, which showed that the adequacy of the model has its statistical significance $(\mathrm{p}<.001)$. And the explanatory power of model 2 in which resilience were inserted as a moderating variable is found to be $25 \%$ ( $\mathrm{R} 2=.253$ ), which increased by .039 compared to that of Model 1. Though the value of F decreased by .191\%, it was statistically significant. In other words, model 2 showed that the job performance was well explained by putting in the resilience. In model 3, which was put in to confirm the interaction between adversity quotient factors and resilience on the part of tax officials, the modified explanatory power of the model increased .007 compared to model 2 as $25 \%$ ( $\mathrm{R} 2=.251$ ), and F value decreased to 9.192 , but it was statistically significant $(\mathrm{p}<.001)$. This result can be seen as a significant one in explaining the interaction between adversity quotient factors and resilience.

Focused on model 2, the ownership $(=.178, \mathrm{p}=0.002)$ and range $(=.116, \mathrm{p}=0.022)$ included in the category of the adversity quotient factors had a significant positive (+) effect on job performance, and the resilience $(=.253, \mathrm{p}=0.000)$ also had a statistically significant effect on job performance. Therefore, the adversity quotient factor had a positive effect on job performance, so hypothesis 1 was adopted. Once the interaction terms were examined in detail in the model 3, the ownership consciousness $\mathrm{x}$ flexibility and range $\mathrm{x}$ flexibility had a significant effect on job performance, but the control $\mathrm{x}$ flexibility and persistence $\mathrm{x}$ flexibility had no moderating effect, so the hypothesis 2-1 and hypothesis 2-4 were rejected whereas the hypothesis 2-2 and hypothesis 2-3 were adopted.

\section{The Conclusion}


This study aimed to empirically investigate the relationship between adversity quotient factors, resilience and job performance of tax officials. This is considered meaningful in that it provides implications for enhancing the job performance of tax organizations.

The results of analyses are as follows.

First, the adversity quotient factors affecting job performance were control $(\mathrm{B}=.111$, $\mathrm{p}=0.044)$, ownership $(\mathrm{B}=.242, \mathrm{p}=0.019)$, reach $(\mathrm{B}=.122, \mathrm{p}=0.000)$ and endurance $(\mathrm{B}=.095$, $\mathrm{p}=0.038$ ). So, hypothesis $1-1$, hypothesis $1-2$, hypothesis $1-3$, hypothesis $1-4$ were supported. Also, the regression coefficient (b) sign was positive (+), and therefore the higher the perception of adversity, the higher the job performance. Such results have a positive effect on job performance, and they are consistent with the result of previous studies that stated that adversity quotient factors have a comprehensive positive effect. This study also confirms the results of the existing studies.

Second, it is shown that the main effect in the moderating regression analysis that resilience would control the relationship between adversity quotient factors and job performance was meaningful, but, in the interaction term, only ownership and range were supported in this study. The sense of ownership allows people with excellent ability to overcome the crisis and to flexibly cope with various ways of changing environment or situation. To this end, the boss must recognize the difference in the subordinates' individual interest and desire so that they can exercise their potential, and the ownership will be inspired through personal consideration. This means that they are possessing the ability to see their responsibility in the overall perspective.

\section{References}

[1] Lee Kwang-Su, "The influence of performance-contingent reward on the job effort and job performance through work motivation," The Journal of Educational Administration, vol.31, no.2, pp.325-346, (2013)

[2] Jeon Yong-Dae, "Pelationship between interactive use of performance measurement system and work performance: mediating effects of farrness, organization commitment, job satisfaction," $\mathrm{Ph}$. D, Gyeong-Sang National University, Jin-Ju, Korea, (2015)

[3] Kim Mun-Sung and Park Seung-Cheol, "The effect of government employee self-efficacy on the job performance,” Korean Public Management Review, vol.25, no.4, pp.143-161, (2011)

[4] P. Stoltz, "Adversity quotient at work", New York, Harper Business, (2012)

[5] B. E. Compas, B. R. Hinden, and C. A. Gerhardt, "Adolescent development: Pathways and processes of risk and resilience,” Annual Review of Psychology, vol.46, pp.265-293, (1995)

[6] S. S. Luthar and E. Zigler, "Adolescent family structure and educational progress," Psycscan Developmental psychology, vol.12, pp.35-36, (1991)

[7] M. Rutter, "Psychosocial resilience and protective mechanism," Risk and protective factors in the development of psychopathplogy, pp.181-214, (1990)

[8] E. E. Werner and R. S. Smith, "Vulnerable butinvincible: A study of resilient children," New York: McGrawHill, (1982)

[9] Park Hee-Se and Lim Byung-Chun, "Test of causal model for the efficient management of the public servants knowledge in the local administration", The Korea Association for Policy Studies, vol.10, no.2, pp.111-134, (2001)

[10] Kang Yeo-Jin, "The impact of knowledge sharing on work performance: an empirical analysis of the public employees' perceptions in Korea,” Korean Public Administration Quarterly, vol.17, no.2, pp.431-460, (2005) 